\title{
Significance of Immunohistochemical Expression of Survivin in Renal Cell Carcinoma
}

\author{
Maisa Hashem Mohammed, Nagwa Abd El-Sadek Ahmed
}

Department of Pathology, Faculty of Medicine, Sohag University, Sohag, Egypt.

\begin{abstract}
Background: Evasion of apoptosis is an essential alteration for cellular genetic mutation. Survivin is a member of inhibitor of apoptosis protein (IAP) family. Under normal conditions, Survivin is expressed in embryonic and fetal tissues and markedly diminished in mature, differentiated adult tissues. Survivin was found to be re-expressed in multiple solid and hematological human malignant neoplasms. The purpose of this study was to evaluate the expression of Survivin in renal cell carcinoma (RCC), and to find statistically significant associations between Survivin and the tested Clinicopathological parameters. Methods: 39 patients with RCCs who underwent nephrectomy were included in the study. From each RCC specimen, two tissue sections were obtained; one was stained by H\&E stain to determine both RCC phenotype and Fuhrman's nuclear grades. The second tissue section was immunohistochemically stained by anti-human Survivin antibody. Results: The study revealed statistically significant associations between Survivin expression in RCC specimens and RCC histological types $(p=0.002)$, high tumor grade $(\mathrm{p}<0.001)$ and advanced tumor stage $(\mathrm{p}<0.001)$. Conclusion: The study revealed that Survivin is positively correlated to poorly differentiated RCCs with high Fuhrman's nuclear grade and advanced tumor stage.
\end{abstract}

Keywords: RCC- Survivin- Apoptosis

Asian Pac J Cancer Biol, 6 (3), 201-205

Submission Date: 06/08/2021 Acceptance Date: 07/17/2021

\section{Introduction}

Renal cell carcinoma (RCC) is one of the most common malignant urological neoplasms. It accounts for $2-3 \%$ of all malignant tumors affecting adult. RCC is an aggressive disease, it is characterized by poor prognosis owing to the diagnostic delay [1]. Nearly about one third of patients with RCCs present with metastasis in different sites of the body at initial diagnosis [2]. Surgical treatment seems to be the only curative therapy for patients with localized RCC. However, tumor resistance to the currently-available chemotherapeutic agents contributes to cancer progression and the development of the so-called post nephrectomy relapse [3]. The classic prognostic parameters as the histological subtypes, Fuhrman nuclear grading system, occurrence and extent of metastasis, thrombosis of caval veins and tumor coagulative necrosis don't always have the fundamental role for a trustable detection of patient's outcome [4]. Incorporation of both clinical and pathological features in a single prognostic scoring system seems to have new advantages in clinical management of patients with RCC [5]. Tumor biology is still a vague issue; patients with RCCs and having the same tumor phenotype and Fuhrman nuclear grade may experience different outcomes. So, there is an indispensable need to determine new prognostic markers which may help, at the molecular level, to accurately determine tumor aggressiveness and patient outcome [6].

Evasion of apoptosis is an essential alteration for cellular genetic mutation and carcinogenesis by abnormally prolonging cell survival, enhancing accumulation of further genetic mutations and subsequent resistance to immune-surveillance [7].

Survivin is an inhibitor of apoptosis protein (IAP) family. Survivin is a $16.5 \mathrm{kD}$ protein, formed of 142 amino acid long. The gene encoding for human Survivin is located at the telomeric end of chromosome 17 [8]. Survivin is involved in cell cycle regulation, inhibition of apoptosis and promotion of angiogenesis [9]. The expression of Survivin is abundant in embryonic and fetal tissues while it

Corresponding Author:

Dr. Maisa Hashem Mohammed

Department of Pathology, Faculty of Medicine, Sohag University, Sohag, Egypt.

Email: maisaahashem@med.sohag.edu.eg 
is undetectable in normal adult tissues [8]. Previous studies showed over-expression of Survivin in many human solid [10] and hematological malignant neoplasms [11]. Such re-expression may have benefits in tumor prognosis and subsequent development of novel anticancer therapeutic agents [12].

The aim of this study was to investigate the Immunohistochemical expression of Survivin in RCC and to correlate such expression to different Clinicopathological parameters of the tumor.

\section{Materials and Methods}

\section{Clinical data and specimens collection}

Upon approval by the Ethical Committee of Sohag University, thirty-nine patients suffered from unilateral RCCs were included in the study. The patients admitted to the Urology Department of Sohag University Hospital from Jan. 2020 to December of the same year. Open nephrectomy operations were done with removal of the affected kidney and the peri renal fat and Gerota fascia, without resection of the ipsilateral lymph nodes or adrenal glands. All patients gave their informed written consents. Inclusion criteria included patients with primary RCCs, while exclusion criteria included patients who received pre-operative chemo or radiotherapy, and RCC specimens with extensive necrosis. The specimens of RCCs were sent to Pathology Department, Sohag University Hospital. Tumor size was carefully revised and each tumor specimen was classified according to 2016, TNM staging system. From each RCC specimen; formalin-fixed and paraffin-embedded tissue blocks were prepared. From each block; two tissue sections were obtained, one was stained by H\&E stain and the other was subjected to Immunohistochemical staining by anti-human Survivin antibody. H\&E stained sections were used to determine RCC phenotype and Fuhrman's nuclear grade.

\section{Immunohistochemical staining of Survivin}

Formalin-fixed and paraffin-embedded RCC tissue blocks were sectioned into $4 \mu \mathrm{m}$ thick slices. Sections were deparaffinized by being placed in a hot xylene for 10 minutes. Tissue sections were re-hydrated by descending grades of alcohol. In order to block endogenous peroxidase activity; tissue sections were incubated in $3 \% \mathrm{H}_{2} \mathrm{O}_{2}$ for 10 minutes at room temperature. Antigen retrieval was achieved by using $0.01 \mathrm{mmol} / \mathrm{L}$ Citrate buffer fluid at $92^{\circ} \mathrm{C}$. for 20 minutes. Sections were incubated with primary antibody overnight at room temperature with 1:100 dilution of a rabbit monoclonal antibody raised against full length recombinant human Survivin (clone \#1277A, Catalog Number: MAB8861, Concentrated form of $0.1 \mathrm{ml}$, Bio-techne). Tissue sections were incubated with goat serum secondary antibody followed by streptavidin biotin for ten minutes, separated by washing in BPS for five minutes after each step. The reaction products were visualized by immersing the sections in diaminobenzidine (DAB) for 15 minutes at room temperature (ScyTek, P.O. Box 3286- Logan, Utah 84323, USA). slight nuclear counterstaining was done by immersion in Harris'
Hematoxalin for few seconds followed by rapid washing in tap water to remove extra dye. Sections were dehydrated by ascending grades of alcohol. Clearance was done by xylene. Each staining run included positive and negative control sections to confirm that staining systems were working accurately and the positive signals were specific. The positive control tissue sections were prepared from human breast cancer tissue as recommended in the data sheet. Negative control were obtained from RCC tissue sections, but BPS was used instead of primary antibody.

\section{Evaluation of Survivin immunostaining}

Evaluation of Survivin expression was done by using a semi-quantitative scoring method. The intensity of Survivin immune-expression was scored as follows:0 (negative), 1 (weak), 2 (moderate) and 3 (strong). The percentage of positive cells was calculated as follows: $0(0-$ $5 \%), 1(6-25 \%), 2(26-50 \%), 3(51-75 \%)$ and 4 (76-100\%). The final score was calculated by multiplying the intensity score with the percentage of positive cells. Tumors were finally categorized into negative for Survivin expression if the final score was $\leq 1$ and positive for Survivin expression if the final score was $\geq 2$ [13].

\section{Statistical analysis}

Data analysis was done by using SPSS version 20 (Statistical Software Package Version 20). Quantitative data was presented as mean, median and range. Student t-test was used to compare means of two groups. X2 test was used to compare the expression rate between the categories. $\mathrm{P}$ was considered statistically significant if $<0.05$.

\section{Results}

\section{Patients' characteristics}

The current study included 39 patients with primary RCCs. Their ages ranged from 43 to 75 years old $($ mean $=56.92)$. The study included 23 men and 16 women. The resected RCCs were localized in the right kidney in 21 out of 39 patients, while in the remaining 18 patients; the resected tumors were left sided. The longest diameter of the resected RCCs ranged from 4 to $12.5 \mathrm{~cm}$. (mean $=7.1)$. Table (1) describes the clinical parameters of the studied cases.

As regards to tumor histology; RCC specimens were categorized into clear cell RCCs (ccRCCs) and chromophobe RCCs in 30 and 9 patients respectively. Nine out of 30 patients with clear cell RCCs had focal sarcomatoid features in the examined H\&E stained sections. Fuhrman's nuclear grading system was applied to the studied cases. Fuhrman's grade I was detected in 12 out of 39 patients. Grades II, III and IV were detected in 16,1 and 10 patients respectively. According to 2016 TNM staging system; nine patients were T1, while T2 andT3 were detected in 6 and 24 patients respectively. Table (2) describes the clinical parameters of the studied cases. 
Table 1. The Clinical Data of the Studied Populations

\begin{tabular}{lc}
\hline & Variable \\
\hline Age/ Year & \\
Range & $43-75$ years. \\
Mean & 56.92 \\
Tumor size/cm & \\
Range & $4-12.5 \mathrm{~cm}$. \\
Mean & 7.1 \\
Variable & No. of cases \\
Sex & \\
Men & 23 \\
Women & 16 \\
Side involved & \\
Right kidney & 21 \\
Left kidney & 18 \\
\hline
\end{tabular}

Immunohistochemical detection of Survivin

On applying the semi-quantitative scoring method; Survivin positive scores $(\geq 2)$ were detected in 29 cases, while 10 cases were scored as negative for Survivin $(\leq 1)$.

In the Survivin- positive RCC specimens, subcellular localization of Survivin was detected in the cytoplasm and cell membranes with no detected nuclear staining. In addition; Survivin was detected in the cytoplasm of renal tubules of the adjacent normal renal tissues, Figure 1.

The statistical evaluation of Survivin immunostaining findings was compared with the studied clinical and pathological data. There was no statistically significant correlation between Survivin expression, age, sex and/or the side of involved kidney, Table 3 . However, there was a statistically significant association between Survivin immune-expression and the histopathological subtypes of the studied cases $(p=0.002)$. All cases of chromophobe RCCs and ccRCCs with focal sarcomatoid features were positive for Survivin. Also, there was a highly significant association between Survivin and Fuhrman's nuclear grading $(\mathrm{p}<0.001)$. all cases that were labeled as negative
Table 2. Histo-pathological Parameters of the Studied Cases

\begin{tabular}{lc}
\hline Variable & No. of cases \\
\hline Tumor phenotype & 21 \\
ccRCC & 9 \\
Chromophobe & \\
Fuhrman's nuclear grade & 12 \\
Grade I & 16 \\
Grade II & 1 \\
Grade III & 10 \\
Grade IV & \\
TNM staging & 9 \\
T1 & 1 \\
T1a & 8 \\
T1b & 6 \\
T2a & 24 \\
T3a & \\
\hline
\end{tabular}

for Survivin expression, were low Fuhrman's nuclear grades ( grades I and II).

Finally, Survivin immunostaining was found to be statistically associated with the pathological tumor stage $(\mathrm{p}<0.001)$. Survivin positivity was detected in advanced tumor stages (T3a) compared to low tumor stages (T1 and T2a), Table 4.

\section{Discussion}

Regardless of being a physiological or a pathological process, apoptosis functions to remove aged, viral-infected and/or genetically mutant cells. evasion of apoptosis is an important step for a mutant cell to maintain its survival, to enhance further mutant genes accumulation and to escape from the immune system [7]. Survivin is an anti-apoptotic protein. Survivin was found to be expressed in embryonic and fetal tissues, while the expression declines in mature, differentiated and normal adult

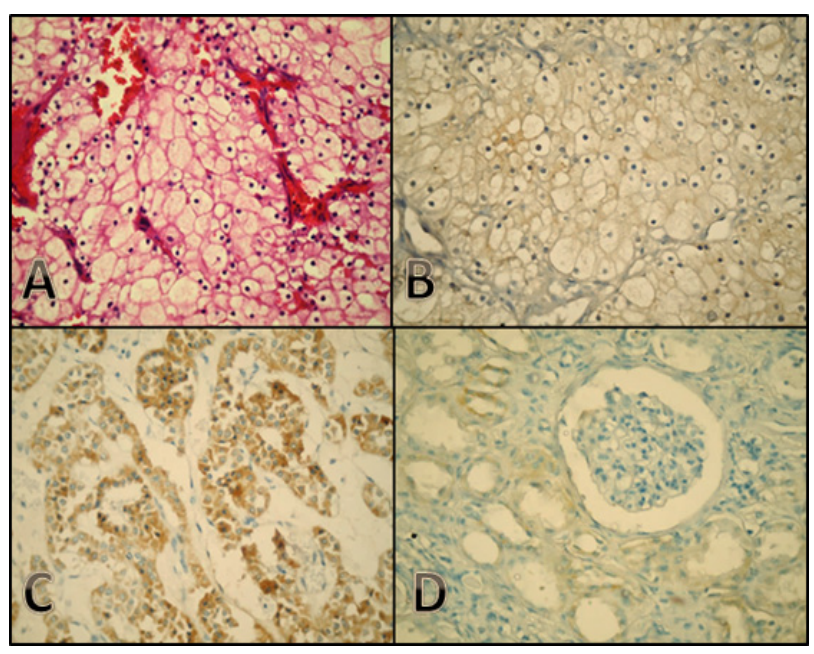

Figure 1. H\&E Staining of ccRCC (A), Immunostaing of Survivin showing Moderate Membranous and Weak Cytoplasmic Staining (B), Strong Cytoplasmic Immunostaining of Survivin (C), Survivin Expression in Normal Renal Tissue showing Tubular Localization (D). x400. 
Table 3. Statistical Analysis of Survivin and the Clinical Parameters

\begin{tabular}{|c|c|c|c|c|}
\hline \multirow[t]{2}{*}{ Variable } & \multicolumn{2}{|c|}{ Survivin Expression } & \multirow[t]{2}{*}{ T- test*or chi- square** } & \multirow[t]{2}{*}{ p-value } \\
\hline & Positive & Negative & & \\
\hline \multicolumn{5}{|l|}{ Age } \\
\hline Mean & 57.65 & 59.7 & $0.859^{*}$ & 0.396 \\
\hline \multicolumn{5}{|l|}{ Sex } \\
\hline Men & 18 & 5 & $0.448^{*}$ & 0.711 \\
\hline Women & 11 & 5 & & \\
\hline \multicolumn{5}{|l|}{ Involved kidney } \\
\hline Right kidney & 16 & 5 & $0.080 * *$ & 0.532 \\
\hline Left kidney & 13 & 5 & & \\
\hline
\end{tabular}

Table 4. Statistical Analysis of Survivin and the Histopathological Parameters

\begin{tabular}{|c|c|c|c|c|}
\hline \multirow[t]{2}{*}{ Variable } & \multicolumn{2}{|c|}{ Survivin Expression } & \multirow[t]{2}{*}{ Chi-square } & \multirow[t]{2}{*}{ p-value } \\
\hline & positive & negative & & \\
\hline \multicolumn{5}{|l|}{ Tumor subtype } \\
\hline ccRCC. & 20 & 10 & 12.776 & 0.002 \\
\hline ccRCC without sarcomatoid features. & 11 & 10 & & \\
\hline ccRCC with sarcomatoid features. & 9 & 0 & & \\
\hline chromophobe RCC & 9 & 0 & & \\
\hline \multicolumn{5}{|l|}{ Fuhrman's nuclear grade } \\
\hline G I & 3 & 9 & 22.282 & $<0.001$ \\
\hline G II & 15 & 1 & & \\
\hline G III & 1 & 0 & & \\
\hline G IV & 10 & 0 & & \\
\hline \multicolumn{5}{|l|}{ T-stage } \\
\hline $\mathrm{T} 1$ & 4 & 5 & 16.491 & $<0.001$ \\
\hline Т 2 & 2 & 4 & & \\
\hline Т 3 & 23 & 1 & & \\
\hline
\end{tabular}

tissues. However, expression of Survivin is up-regulated many human malignant neoplasms [8]. Hsu and co-workers performed a study on a series of 46 patients with esophageal carcinomas. They found that the high expression of Survivin was positively correlated with the degree of tumor differentiation. They also recommended the use of Survivin as a prognostic marker for esophageal carcinoma [14]. Shariat and colleagues compared the expression of Survivin in normal and neoplastic urinary bladder tissues, they found that Survivin was not detected in normal urinary bladder tissues, while it was expressed in bladder carcinoma specimens. Furthermore, Survivin expression was noticed to be increased in cases with positive nodal metastasis [15]. In our study, we evaluated the expression of Survivin in 39 patients with RCCs, and we correlated such expression with different clinical and pathological parameters of the studied cases. We found a statistically significant association between Survivin expression and RCC subtypes. All the studied cases of chromophobe RCCs and ccRCCs with focal sarcomatoid features showed high Survivin immunostaining. Wang and co-workers demonstrated high Survivin immunostaining scores in sarcomatoid-featuring RCCs compared to RCC specimens without sarcomatoid foci, and they hypothesized that Survivin expression was augmented in advanced and more aggressive variants of RCCs [16]. Actually, the association between Survivin expression and the more aggressive RCC variants may have a promising hope in developing novel anti-cancer therapeutic agents that target Survivin. Statistically significant associations have been observed between Survivin expression on one side and high tumor grades and advanced stages on other side. This was keeping with what observed by Shi and colleagues. They evaluated the Immunohistochemical expression of Survivin in a series of 65 cases of ccRCCs and adjacent normal renal tissues. They postulated that Survivin expression is markedly increased in neoplastic renal tissues, compared to the nearby non-neoplastic renal tissues, and Survivin expression is augmented in advanced RCC grades and stages [13]. Furthermore, Zamparese and co-workers observed the expression of Survivin in a series of 49 patients with ccRCCs. They reported that Survivin expression was significantly accentuated in poorly differentiated RCCs [3]. Associations between Survivin expression, high tumor grade and advanced stages can be explained on the basis that expression of Survivin gene occurs in $\mathrm{G} 2 / \mathrm{M}$ phase in a strictly controlled cell cycle. [8]. Malignant tumors, including RCCs, have 
high proliferative potential which enhance Survivin over-expression. Autonomous expression of Survivin in highly proliferated neoplastic cells inhibits cell apoptosis, facilitates cumulative genetic mutations. The neoplastic cells, in turn, become more de-differentiated and acquire more enhanced invasive capacities.

In conclusion, our study proved that RCCs express Survivin, and such expression is positively correlated to poorly differentiated RCCs with high grades and advanced stages. Also, the current study supports the probable benefits of targeting Survivin molecules in developing RCC immune-therapeutic agents in the future.

\section{Conflict of interest}

The authors declare that they have no conflict of interest.

\section{References}

1. Xie Y, Ma X, Gu L, Li H, Chen L, Li X, Gao Y, Fan Y, Zhang Y, Yao Y, Zhang X. Prognostic and Clinicopathological Significance of Survivin Expression in Renal Cell Carcinoma: A Systematic Review and Meta-Analysis. Scientific Reports. 201607 14;6(1). https://doi.org/10.1038/ srep29794

2. Athar U G. Treatment options for metastatic renal cell carcinoma: a review. Can J Urol. 2008;15(2):3954-66. 2008;15(2):3954-66.

3. Zamparese R, Pannone G, Santoro A, Muzio LL, Corsi F, Pedicillo MC, Scillitani EL, Tortorella S, Staibano S, Piscuoglio S, Russo LL, Bufo P. Survivin Expression in Renal Cell Carcinoma. Cancer Investigation. 2008 01;26(9):929935. https://doi.org/10.1080/07357900802017553

4. Sengupta S, Lohse CM, Leibovich BC, Frank I, Thompson RH, Webster WS, Zincke H, Blute ML, Cheville JC, Kwon ED. Histologic coagulative tumor necrosis as a prognostic indicator of renal cell carcinoma aggressiveness. Cancer. 2005;104(3):511-520. https://doi.org/10.1002/cncr.21206

5. Leibovich BC, Blute ML, Cheville JC, Lohse CM, Frank I, Kwon ED, Weaver AL, Parker AS, Zincke H. Prediction of progression after radical nephrectomy for patients with clear cell renal cell carcinoma. Cancer. 200303 18;97(7):16631671. https://doi.org/10.1002/cncr.11234

6. MÉJEAN A, OUDARD S, THIOUNN N. Prognostic Factors of Renal Cell Carcinoma. Journal of Urology. 2003 03;169(3):821-827. https://doi.org/10.1097/01. ju.0000051378.14270.2a

7. Mahotka C, Liebmann J, Wenzel M, Suschek CV, Schmitt M, Gabbert HE, Gerharz CD. Differential subcellular localization of functionally divergent survivin splice variants. Cell Death \& Differentiation. 2002 Dec;9(12):13341342. https://doi.org/10.1038/sj.cdd.4401091

8. Mittal R, Jaiswal P, Goel A. Survivin: A molecular biomarker in cancer. Indian Journal of Medical Research. 2015;141(4):389. https://doi.org/10.4103/0971-5916.159250

9. Sah N, Khan Z, Khan G, Bisen P. Structural, functional and therapeutic biology of survivin. Cancer Letters. 2006 Dec;244(2):164-171. https://doi.org/10.1016/j. canlet.2006.03.007

10. Ryan B, Konecny G, Kahlert S, Wang H, Untch M, Meng G, Pegram M, Podratz K, Crown J, Slamon D, Duffy M. Survivin expression in breast cancer predicts clinical outcome and is associated with HER2, VEGF, urokinase plasminogen activator and PAI-1. Annals of Oncology. 2006
04;17(4):597-604. https://doi.org/10.1093/annonc/mdj121

11. Ambrosini G, Adida C, Altieri DC. A novel anti-apoptosis gene, survivin, expressed in cancer and lymphoma. Nature Medicine. 1997 08;3(8):917-921. https://doi.org/10.1038/ nm0897-917

12. Altieri DC. Survivin, cancer networks and pathway-directed drug discovery. Nature Reviews Cancer. 2008 01;8(1):61-70. https://doi.org/10.1038/nrc2293

13. Shi Z, Li S, Li Z, Zhu X, Xu P, Liu G. Expression of vimentin and survivin in clear cell renal cell carcinoma and correlation with p53. Clinical and Translational Oncology. 201407 16;17(1):65-73. https://doi.org/10.1007/s12094-014-1199-1

14. Hsu KF L, Yu C, Tzao C, Lee S, Lee Y, Tsai W, Jin J. Cortactin, fascin and survivin expression associated with Clinicopathological parameters in esophageal squamous cell carcinoma. Dis Esophagus. 2009;22(5):402-8.

15. Shariat SF, Ashfaq R, Karakiewicz PI, Saeedi O, Sagalowsky AI, Lotan Y. Survivin expression is associated with bladder cancer presence, stage, progression, and mortality. Cancer. 200703 15;109(6):1106-1113. https://doi.org/10.1002/ cncr. 22521

16. Wang G, Hsieh P, Hsu H, Sun G, Nieh S, Yu C, Jin J. Expression of cortactin and survivin in renal cell carcinoma associated with tumor aggressiveness. World Journal of Urology. 200902 15;27(4):557-563. https://doi.org/10.1007/ s00345-009-0376-2

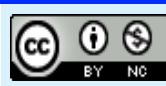

This work is licensed under a Creative Commons AttributionNon Commercial 4.0 International License. 